\title{
Tabes dorsalis with sudden onset of paraplegia
}

\author{
A. K. GHOSH* AND S. HOLT $†$ \\ From the Department of Venereology*, Liverpool Royal Infirmary, and Broad Green Hospital $\dagger$, Liverpool
}

Tabes dorsalis frequently causes diagnostic problems. Cases of late syphilis are often admitted to hospital incorrectly diagnosed or with unusual complications. The diagnosis of neuro-syphilis may be suspected only when routine serological tests for syphilis are found to be positive. Tabes dorsalis with Charcot's arthropathy, spinal cord compression, and cauda equina lesions may occur more frequently than is generally recognized (Serre, Gros, Simon, Baumelou, and Lamboley, 1970; de Sèze, Hubault, Hamonet, Dudognon, and Prost, 1972. Alergant (1960) reported two cases of tabetic spinal arthropathy with motor symptoms due to anterior nerve root compression and stressed the importance of observing these cases indefinitely. Gumma of the spine is extremely rare. A case of gummatous spondylitis was described by Hannuksela and Karaharju (1972). The following case is reported because of the rarity of gummatous lesions of the spine and because the subsequent complications aroused considerable interest amongst physicians, neuro-surgeons, and venereologists.

\section{Case report}

A 57-year-old long-distance lorry driver, who was a known sufferer from tabes dorsalis, was first referred to the venereology unit at Newsham General Hospital, Liverpool, on June 19, 1974.

In 1944 he had been treated for gonorrhoea at Liverpool Royal Infirmary when he received a single penicillin injection and was apparently followed for 3 months after treatment, but no medical notes of this attendance are available. On June 9, 1962, he presented at a Medical Clinic of Whiston Hospital with a history of shooting pains in the lower limbs. Clinical examination revealed that knee and ankle jerks were absent and deep pain and vibration sensation in the legs was impaired. The pupils were small and reacted to accommodation but only sluggishly to light. The blood Wassermann reaction was strongly positive and the cerebrospinal fluid showed 54 lymphocytes $/ \mathrm{ml}$., excess of globulin, and a strongly positive Wassermann reaction.

Tabes dorsalis was diagnosed and he was treated with procaine penicillin $1.2 \mathrm{~m}$.u. daily for 10 days. Apparently he improved and he was discharged after only one year's observation.

Received for publication February 17, 1975

Address for reprints: Dr. A. K. Ghosh, Liverpool Royal Infirmary, Pembroke Place, Liverpool L3 5PU
Over the ensuing years he continued his job, but still experienced occasional shooting pains in both legs and an intermittent sharp rectal pain also started.

He was referred to Broadgreen Hospital on March 4, 1969, for further investigations. Examination of stools, sigmoidoscopy, and a barium enema did not reveal any local cause and the rectal pain was considered to be due to tabetic crises. He received two further courses, 3 months apart, of benzyl penicillin (soluble penicillin) in a dose of $2 \mathrm{~m}$.u. daily for 10 days. Shortly after this treatment he developed upper abdominal pain. This was investigated and the barium meal was found to be normal. In view of the previous history, this was considered to be a gastric tabetic crisis.

The patient continued to work until April, 1974, when he developed weakness in the lower limbs accompanied by a moderate degree of ataxia. This was soon followed by sharp shooting pains in the back and in both legs, and he was re-admitted to hospital on May 21, 1974. Shortly after admission the weakness in the lower limbs increased culminating in flaccid paraplegia. There was a complete motor and sensory loss in the lower limbs and retention of urine with overflow. Radiology of the lumbar spine on admission showed osteophytic lipping with marked changes in the L1 and L2 vertebrae suggesting Charcot's arthropathy. Another $x$ ray of the lumbar spine after the onset of paraplegia showed the collapse of L5. He was then transferred to the Regional Neurological Unit at Walton Hospital. An emergency myelogram showed a block at the level of L3 and L4 with fairly symmetrical narrowing of the subarachnoid space on both sides. The body of L5 was noted to be collapsed with preservation of the disc space (Figs 1 and 2). Neoplasm was considered to be the most likely pathology and the patient underwent laminectomy on May 23, 1974.

\section{Surgery}

At operation, no obvious neoplasm was found, but a large cavity was encountered at the level of L5 and nondescript softish tissue was removed for histological examination.

\section{Histological studies}

The material removed showed chronic granulation with infiltration of lymphocytes and evidence of periarteritis and endarteritis; there was no evidence of tuberculosis or neoplasm.

\section{Laboratory investigations}

The blood picture, chest $x$ ray, serum proteins with electrophoresis, serum calcium and phosphate, and complete urine analysis were all normal. Standard tests 

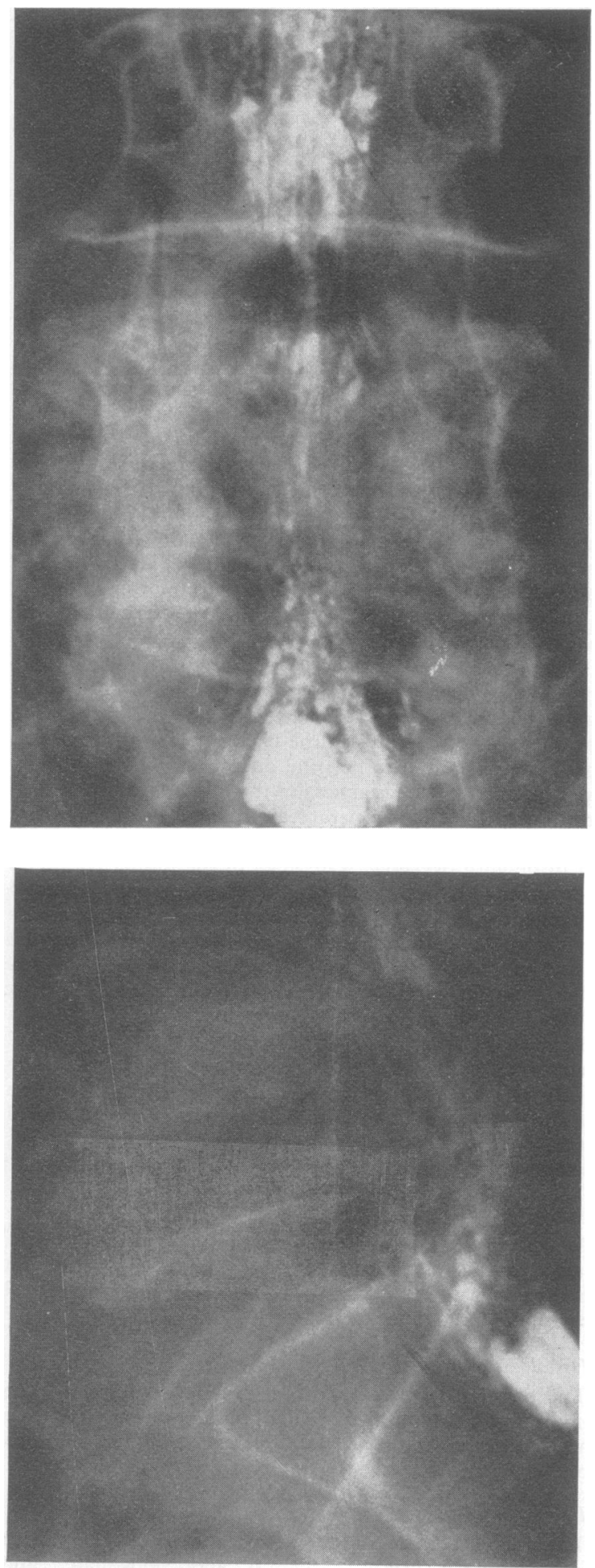

FIGS 1 AND 2 Radiological appearances of L5 for syphilis on the cerebrospinal fluid were reported to be negative, but serological studies showed:

$\begin{array}{ll}\begin{array}{l}\text { Treponema pallidum } \\ \text { haemagglutination test }\end{array} & \text { Positive } 1 \text { in } 16 \\ \begin{array}{l}\text { Cardiolipin Wassermann } \\ \text { reaction }\end{array} & \text { Weakly reactive } \\ \begin{array}{l}\text { Reiter protein complement- } \\ \text { fixation test }\end{array} & \text { Weakly reactive } \\ \text { FTA-ABS test } & \text { Positive }\end{array}$

Result

Postoperatively, a moderate degree of motor function of the legs was regained, and it was at this stage that the patient came under the care of a venereologist under whose supervision he was admitted to Newsham General Hospital on June 19, 1974. Procaine penicillin $1.2 \mathrm{~m} . u$. was given daily for 3 weeks, with intensive active physiotherapy and occupational therapy. The therapeutic response was satisfactory, with considerable symptomatic and objective improvement, and the patient was finally discharged after 8 weeks. Serological tests for syphilis showed his children and his wife to be negative.

\section{Comment}

This case has the following main points of interest which may or may not have some bearing on the prognosis.

(1) Tabes dorsalis was diagnosed in 1962 but no venereologist had been consulted until 1974 .

(2) After the first rather short course of penicillin for the above condition he was followed up for only one year, and apparently without proper follow-up tests such as the cerebrospinal fluid examination which was found to be abnormal at the time the diagnosis of tabes dorsalis was made.

(3) His condition deteriorated 7 years later and he began to experience tabetic crises; he then received one injection daily of benzyl (soluble) penicillina régime which would hardly have any place in the treatment of syphilis.

(4) Although he had been treated for tabes dorsalis, he developed spinal Charcot's arthropathy and a spinal gumma. Gummatous lesions in neurosyphilis, particularly in treated cases, are rare indeed.

In conclusion, although gummatous lesions of the vertebrae in tertiary syphilis are rare, this case illustrates that a gumma should be borne in mind as one of the aetiological factors in the differential diagnosis of paraplegia of sudden onset. Surgical intervention may then be considered to be a matter of urgency as in this case.

\section{Summary}

A case is presented of tabes dorsalis with spinal gumma producing collapse of the L5 vertebra followed by paraplegia. 
I wish to thank Dr. F. Lanceley, Consultant Venereologist, for allowing me to report this case, and to Dr. O. P. Arya, Consultant Venereologist, for assistance in preparing this work. I also wish to thank Mrs. B. Pritchard for typing the manuscript.

\section{References}

Alergant, C. D. (1960) Brit. F. vener. Dis., 36, 261
HanNuksela, M., and Karaharju, E. O. (1972) Ibid., 48, 397

Serre, H., Gros, C., Simon, L., Baumelou, H., and Lamboley, C. (1970) Bull. Acad. nat. méd. (Paris), 154, 212

Sèze, S. de, Hubault, A., Hamonet, C., Dudognon, P., and Prost, A. (1972) Nouv. Presse méd., 1, 2747

\section{Book Review}

A Short Textbook of Venereology. The Sexually-Transmitted Diseases. 2nd ed., 1974. By R. D. Catterall. Pp. 214, 50 figs. English

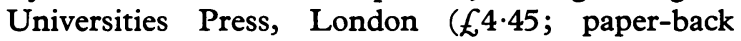
$£ 2 \cdot 25)$

The second edition of this excellent short text book has had to be completely revised in view of the advances in the field of venereology during the last 10 years. The attempt to take a global view of medicine is to-day essential in view of the increasing availability of air travel and the greater awareness of the magnitude of the problem of sexually-transmitted diseases in Africa, Asia, and elsewhere.

The initial chapter provides a lucid description of the practice of venereology with its attendant public health, educational, and social problems. The section on gonorrhoe occupies just over 10 per cent of the total text, and while this may seem insufficient in view of the pandemic with this organism, little of value has been omitted. The repetition of the differential diagnosis of both urethral discharge and vaginal discharge throughout the book, is of value to the undergraduate and postgraduate student who has had little previous experience in the field. The author is to be congratulated on the comprehensive chapter on the examination of patients and in the emphasis throughout the book that the practice of venereology is not an isolated entity but an integral part of the spectrum of medicine.

There will always be minor criticisms and personal therapeutic preferences. Many would prefer not to discuss keratodermia blennorrhagica in relation to acute gonorrhoea, and perhaps spectinomycin is a suitable alternative parenteral therapy for gonorrhoea in patients with a history of penicillin sensitivity.

The author's first edition was a landmark in venereology textbooks, providing a short, comprehensive, and inexpensive text on the practice of this aspect of Medicine; the second edition continues the tradition.

F. R. W. Harris

o

